\title{
V031 HORIZONTAL DRILLING AND IMPEDANCE MODEL - A 3D INVERSION CASE STUDY
}

\author{
P. LANFP.ANCHI', R.M. ELDE' ${ }^{2}$, T. COLEOU ${ }^{1}$ and H.E. RO ${ }^{2}$ \\ ${ }^{\prime}$ CGG, Oslo Processing Centre, PO Box 243, 1322 Hovik, Norway \\ ${ }^{2}$ Norsk Hydro Production
}

\section{Introduction}

Today, one main challenge for the seismic industry is to provide accurate and reliable information to describe hydrocarbon reservoirs. Such reservoirs are characterized by:

i/ their geometry,

ii/ their lithology and fluid content,

iii/ their petro-physical parameters (porosity, permeability,...).

Item $\mathrm{i}$ / is generally addressed with depth imaging techniques which are now able to account for more and more complex structures.

It is difficult to tackle item ii/ with conventional seismic data for two reasons:

- first, a seismic dataset is driven by the convolutions of seismic wavelets by reflection coefficient series. Seismic reflectors are the result of constructive and destructive interferences, and therefore are unable to describe the lithological layering of a reservoir;

- secondly, the strength of a seismic reflection is controlled by the differential change of impedance. This lack of sensitivity to absolute impedance values prevent conventional seismic data to be used for accurate lithology prediction.

Nevertheless, there is enough information encoded in seismic experiments to derive impedance values, provided the processing sequence is able to preserve the recorded amplitudes. Ideally, an impedance dataset overcomes the main drawbacks previously listed. Together with rock physics and geostatistical methods, the impedance models can lead to peiro-physical parameters estimation (iii/ item).

In this paper, we present a case study on deriving a 3D impedance model for the Troll West Oil Province. In a first step, the results have been successfully correlated with existing drillings. After this first validation, they have been used to improve the geological models and to guide horizontal drillings in the reservoir.

\section{Field description}

The Troll Field is divided by two major, curved north-south trending faults which separate the field in three easterly tilted fault blocks named Troll Oil Oil Province (TOOP), Troll Oil Gas Province (TOGP) and Troll East.

The hydrocarbon bearing sediments in the Troll Field belong to the Sognefjord Formation. These sediments consist of alternating layers of the two kinds of sands:

- C-sand: clean, moderately to poorly sorted, middle to coarse sandstone, with permeability in the range [1-30] Darcy;

- M-sand: micaceous, silty and fine grained sandstone, with permeability varying from 10 to some hundred milliDarcy.

Intervals of calcite cemented zones are found throughout the reservoir sequence and mainly at, or near boundaries between the C- and M-sands. In the TOOP and TGOP the oil bearing part of the Sognefjord Formation consists of delta front sediments with several sand lobes, each consisting of $\mathrm{C}$ - and $\mathrm{M}$-sands.

To successfully be able to produce the thin oil zone of the TOOP and TGOP, 22-26 and 12-14 meters respectively, the oil producing wells have to be located within $\mathrm{C}$-sand and away from the thicker calcite cemented zones. This implies that mapping of individual sand bodies and boundaries is crucial for the success of the field development. So far, three main sequence boundaries within the Sognefjord Formation are fairly confidently mapped on TOOP and TGOP.

However, in the northern part of the TOOP, the upper part of the Sognefjord Formation consists of several weak and confusional reflectors, leading to an uncertain geological model. In particular, thick stringers of calcite cementation failed to be identified. Since these calcite cemented zones are mainly connnected to boundaries between different sand bodies, their mapping was one of the goals of the inversion. 


\section{Amplitude control}

The 3D volume used for the inversion has to meet certain conditions: the dataset should be multiple free, zerooffset migrated and near zero-phased. Furthermore, since the inversion process tends to extract the information encoded into the seismic amplitudes, a special attention should be paid to their preservation: To get reliable information, we need to ensure that any amplitude variation is related to a genuine geological effect. The processing therefore has to remove acquisition imprint, noise, propagation effects and numerical artifacts without using any conventionnal AGC. We used a powerful method to perform global QC via 3D attributes (Manin et al., 1994). After each key step of the processing sequence, amplitude maps have been derived in order to make sure that no undesired effects were created. Following this methodology, we produced a suitable dataset, with no remaining amplitude artifacts that could corrupt the reliability of the inversion results.

\section{The inversion method}

A true 3D algorithm has been used in order to decrease the noise level and to improve the spatial consistency of the results (Gluck et al., 1994). Starting from an initial model and a single regional wavelet, the program computes the synthetic seismic response of a suite of impedance models. The model space (impedance and two-way travel time) is explored until the distance between the current model response and the actual seismic dataset stabilizes. The convergence of the method is ensured through a simulated annealing technique suitable to handle local minima generated by large sets of non-linear equations.

\section{The a priori macro-model}

The a priori macro-model is a key step since it underlies the global strategy of the overall methodology. We use a sparse parametrization for both times and impedances. 10 horizons have been picked in the target window (1500$1900 \mathrm{~ms}$ ). In the macro-layers defined by these horizons, we set impedance values (constant and space variant) derived from two available wells. We used the low frequency trend of the impedance logs to constrain the impedance in each macro-layer of the model.

\section{Results}

The goal of this inversion was to get useful insights into the following issues:

- Top and Base reservoir delineation

- Separation between individual sand units within reservoir

- Discrimination between high and low permeability zones

- Tracking of Calcite cementation.

A stratified 3D impedance model has been produced. For each "micro-layer" of the optimal model, impedance, time and time thickness are automatically mapped. First, the results have been validated with existing vertical and horizontal wells. A good correlation was observed along the well-path although no quantitative study has been performed so far. In a second phase, results have been used to update the geological model and to guide the drilling program. The main issues were to avoid high impedance calcite formations and to keep the well in the high permeability/low impedance layer.

\section{Conclusion}

We have shown how an impedance cube derived from 3D seismic dataset can be successfully used to improve geological models and to refine the drilling planning of the new wells. Furthermore, we think that $3 \mathrm{D}$ inversion is now a mature technique that can be used for a wide range of practical application in reservoir management.

\section{Acknowledgements}

The authors would like to thank S. Gluck (CGG France) who wrote the inversion program, Y. Lafet (CGG France) for his valuable advice and the Troll unit members for the permission to publish this paper.

The presented ideas only reflect the authors standpoint.

\section{References:}

S. Gluck, F. Huguet, D. Mougenot, 1994, Stratigraphic inversion of 3D Seismic: Comparison of 1D, 2D and 3D approaches for describing a complex reservoir, EAEG workshop, Vienna.

M. Manin, M. Brink, 1994, Global QC via 3D attribute mapping - North Sea Case histories, NPF conference. 